\title{
NUMERICAL CALCULATION METHOD FOR PREDICTION OF GROUND-BORNE VIBRATION NEAR SUBWAY TUNNEL
}

\author{
Masaru Furuta $*^{1}$, Kiwamu Tsuno $*^{2}$ and Kazuhisa Abe $*^{3}$ \\ *1 Bureau of Transportation,Tokyo Metropolitan Government, Masaru_Furuta@member.metro.tokyo.jp \\ *22 Structures Technology Division, Railway Technical Research Institute, tsuno@ rtri.or.jp \\ *33 Department of Civil Engineering and Architecture, Niigata University, abe@eng.niigata-u.ac.jp
}

\begin{abstract}
This paper describes the outline of prediction method including the model for train/track/tunnel and that of wave propagation in the ground, which has been developed to predict the subway-induced vibration propagated to the ground surface in consideration of frequency characteristics. Prediction example and verification by field measurement are also carried out at a subway shield tunnel.
\end{abstract}

\section{INTRODUCTION}

In recent days, as densely populated urban areas necessitate high utilization of space, railway tunnels have been constructed close to existing structures. On the other hand, new facilities requiring silence and vibration free have been constructed close to the railway tunnels. Such situations have required the accurate estimation against the train-induced vibration, in some cases, including the ground-borne noise.

Some empirical equations [1] have been already proposed to predict vibration level on the ground surface. These equations, however, focus on the ground-borne vibration below $80 \mathrm{~Hz}$ and do not predict the high frequency components more than $80 \mathrm{~Hz}$. They do not cover the spectra such as the vibration acceleration level in one-third octave band. Therefore, the authors have been developed the prediction method of generated vibration based on a model for train/track/tunnel [2-3] and that of wave propagation in the ground [4-5]. This paper describes the outline of prediction method, prediction example and verification by field measurement at a subway shield tunnel.

\section{FIELD MEASUREMENT AT SUBWAY TUNNEL}

\subsection{Outline of measurement}

Field measurement is carried out at a subway shield tunnel in the Tokyo area [6]. Figure 1 illustrates the configuration and ground profile of measurement site, tunnel shape and measurement points. The ground surface is covered with soft alluvial sandy or clayey soil, while the tunnel of $10.4 \mathrm{~m}$ in diameter is located in diluvial sand. The tunnel overburden is $15.8 \mathrm{~m}$ and the tunnel lining consists of $55 \mathrm{~cm}$-thick concrete segments and $25 \mathrm{~cm}$-thick secondary lining. Eight-car trains of $20 \mathrm{~m}$ in length pass at speeds of $45 \mathrm{~km} / \mathrm{h}$ and the track is ballast track with $20 \mathrm{~mm}$ - thick ballastmats.

Vibration acceleration is simultaneously measured in the tunnel, on the ground surface and in the ground by using piezoelectric accelerometers, charge amplifiers and data recorders. To directly measure the vibration propagated through the ground, accelerometers placed in three waterproof vessels are installed at the depth of 5, 15 and $25 \mathrm{~m}$ inside the borehole $2 \mathrm{~m}$ distant form the tunnel sidewall. The void space between waterproof vessels is filled with sand with sufficient tamping.

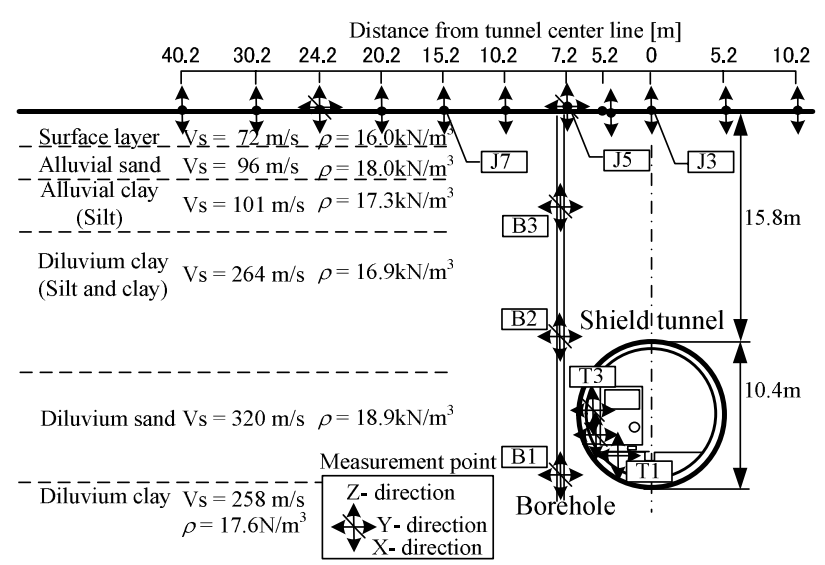

Fig.1 Outline of field measurement at a shield tunnel [6]

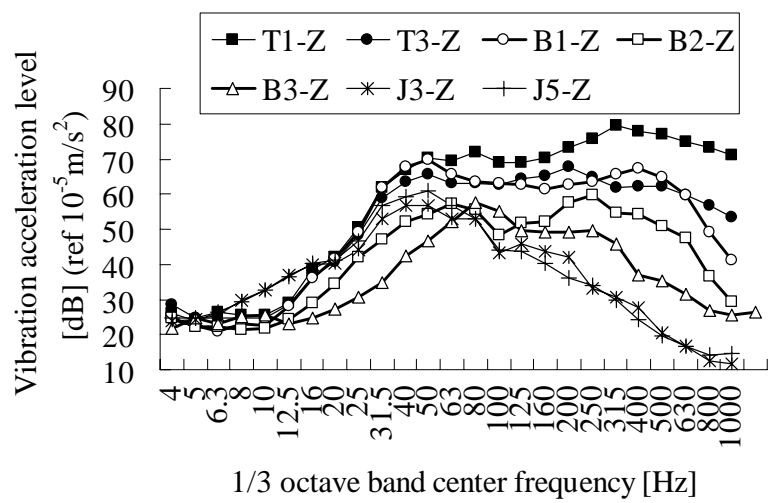

Fig.2 Vibration acceleration level in one-third octave band 


\subsection{Measurement result}

Figure 2 shows the spectra of representative measurement points in the Z- (vertical) direction. Vibration acceleration level in one-third octave bands (abbreviated as "VAL in $1 / 3$ octave bands") is calculated with a time constant of 1 second by the arithmetical mean of peak values for six or more passing trains, after eliminating the data strongly influenced by wheel damage, background and other obstacles. The reference value is $10^{-5} \mathrm{~m} / \mathrm{s}^{2}$ in conformity to Japanese Industrial Standards.

In the tunnel (T1, T3), VAL in $1 / 3$ octave bands is minimal below $16 \mathrm{~Hz}$ and tends to increase with frequency from $16 \mathrm{~Hz}$ to $50 \mathrm{~Hz}$ and the spectra have high frequency components more than $200 \mathrm{~Hz}$. The figure also shows that the spectra on the ground surface $(\mathrm{J} 3, \mathrm{~J} 5)$ have absolute peaks at $50 \mathrm{~Hz}$. As compared with the spectra near the track, in the ground (B1, B2, B3) and on the ground surface, the components higher than $160 \mathrm{~Hz}$ gradually attenuate and absolute peaks near $50 \mathrm{~Hz}$ becomes clear, as the measurement points approach to the ground surface. It is possible to observe the amplification near the ground surface by comparing the spectrum of B3-Z with that of J5-Z.

\section{PREDICTION OF VIBRATION GENERATION}

\subsection{Calculation model}

To calculate the vibration generated in subway tunnels, train/track/tunnel interaction model has been investigated and developed as shown in Fig.3 [2]. Cars, tracks, a tunnel and the ground near the tunnel, which were related to each other, are modeled in two-dimensional and one bogie of the car was considered in the model. Wheel and rails are modeled as moving mass and continuous beam, respectively, while pads are the Voigt unit consisting of springs and dashpots. The situation where a train is traveling on the rail of track at a constant speed is analyzed by utilizing the time-history response analysis method.

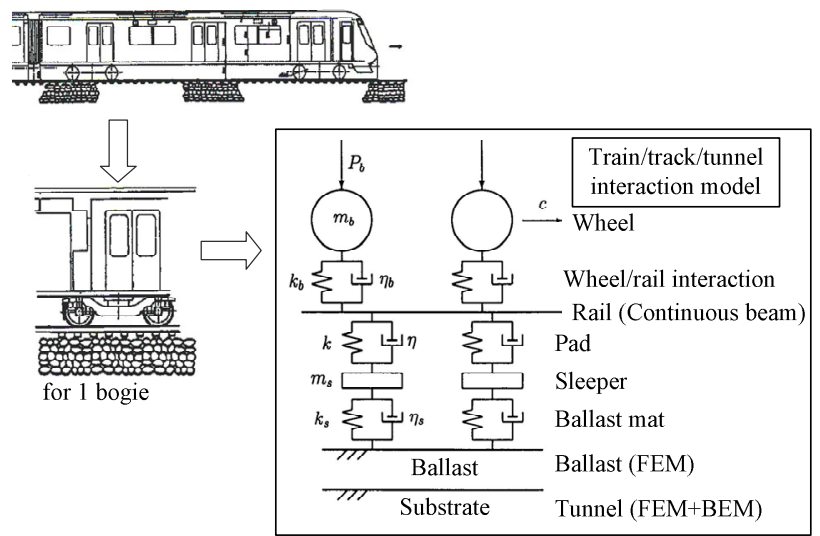

Fig.3 Outline of train/track/tunnel interaction model

\subsection{Calculation of generated vibration in tunnel}

Vibration acceleration near the track is calculated under the condition of Table 1 and 2, which corresponds to the field measurement as described in chapter 2 . Figure 4 shows the input rail roughness, which are obtained by the identification approach based on field measurement of the same subway line [7]. Figure 5 shows calculated acceleration amplitude near the track, which is adjusted to the measured amplitude obtained by the measurement. Calculated VAL in $1 / 3$ octave bands is compared with that obtained by the measurement in Fig.6. It is observed that the calculated spectrum roughly corresponds to that obtained by the field measurement.

Table 1 Basic properties of train and track

\begin{tabular}{l|l|rl}
\hline \multirow{2}{*}{ Train } & Weight of car body & 36.75 & $\mathrm{kN}$ \\
\cline { 2 - 4 } & $\begin{array}{l}\text { Mass of wheel set } \\
\text { (Unsprung mass) }\end{array}$ & 350 & $\mathrm{~kg}$ \\
\hline \multirow{2}{*}{$\begin{array}{l}\text { Wheel/rail } \\
\text { interaction }\end{array}$} & Spring constant & 2000 & $\mathrm{MN} / \mathrm{m}$ \\
\cline { 2 - 4 } & Damping coefficient & 1 & $\mathrm{kN} \mathrm{s} / \mathrm{m}$ \\
\hline \multirow{2}{*}{ Rail } & Flexural rigidity & 4 & $\mathrm{MN} \mathrm{m}$ \\
\cline { 2 - 4 } & Mass & 50 & $\mathrm{~kg} / \mathrm{m}$ \\
\hline \multirow{3}{*}{ Rail pad } & Spring constant (Linear) & 63.4 & $\mathrm{MN} / \mathrm{m}$ \\
\cline { 2 - 4 } & (Non-linear) & $1 \times 10^{10}$ & $\mathrm{MN} / \mathrm{m}$ \\
\cline { 2 - 4 } & Damping coefficient & 650 & $\mathrm{kN} \mathrm{s} / \mathrm{m}$ \\
\hline \multirow{2}{*}{$\begin{array}{c}\text { Sleeper } \\
\text { pad }\end{array}$} & Spring constant (Linear) & 7.8 & $\mathrm{MN} / \mathrm{m}$ \\
\cline { 2 - 4 } & (Non-linear) & $1 \times 10^{10}$ & $\mathrm{MN} / \mathrm{m}$ \\
\cline { 2 - 4 } & Damping coefficient & 100 & $\mathrm{kN} \mathrm{s} / \mathrm{m}$ \\
\hline \multirow{2}{*}{ Sleeper } & Flexural rigidity & 1 & $\mathrm{MN} \mathrm{m}{ }^{2}$ \\
\cline { 2 - 4 } & Mass & 102.5 & $\mathrm{~kg}$ \\
\hline
\end{tabular}

Table 2 Properties of track bed, concrete base and ground

\begin{tabular}{ccccc}
\hline & $\begin{array}{c}\text { Density } \\
{\left[\mathrm{kg} / \mathrm{m}^{3}\right]}\end{array}$ & $\begin{array}{c}\text { Primary wave } \\
\text { velocity }[\mathrm{m} / \mathrm{s}]\end{array}$ & \multicolumn{2}{c}{ Shear wave Shear modulus } \\
velocity $[\mathrm{m} / \mathrm{s}]$ & {$[\mathrm{MN}]$} \\
\hline Track bed & 1667 & 465.0 & 248.6 & 103.0 \\
\hline Ballast mat & 1227 & 70.65 & 49.96 & 3.06 \\
\hline $\begin{array}{c}\text { Concrete } \\
\text { base }\end{array}$ & 2300 & 4768 & 2920 & 19610 \\
\hline Ground & 1420 & 928 & 270 & 22 \\
\hline
\end{tabular}

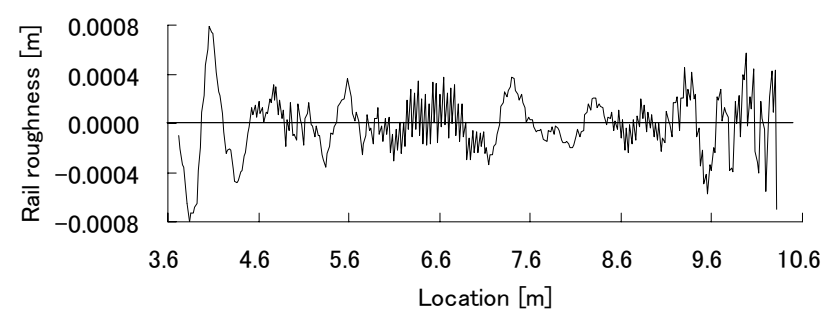

Fig.4 Rail roughness

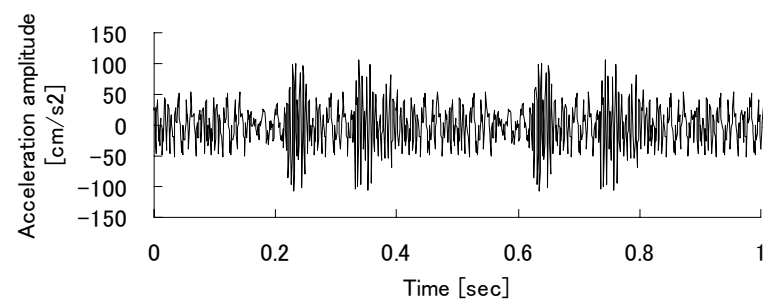

Fig.5 Amplitude of generated vibration (Near the track) 


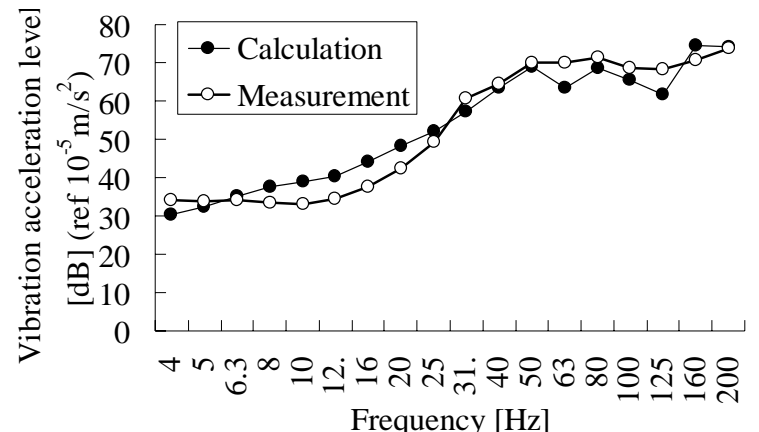

Frequency [Hz]

Fig.6 Calculated and measured vibration acceleration level in one-third octave bands (Near the track)

\section{PREDICTION OF PROPAGATION}

Vibration acceleration on the ground surface is calculated under the same conditions as the field measurement described in chapter2, and the predicted results are compared with the measurement results. The attenuation in the ground is obtained by means of the two methods: an empirical model and numerical analysis (2D-FE analysis). The prediction uses the acceleration amplitude in the tunnel obtained by the train/track/tunnel interaction model (see Fig.5 and 6).

\subsection{Empirical model}

To predict the attenuation in the ground in consideration of frequency characteristics, an empirical model is proposed based on field measurement of 14 locations in the Tokyo area, in which vibration acceleration is measured both in subway shield tunnels and on the ground surface [4, 8]. The conditions of measurement locations are described in Table2. The measurement method is same as described in chapter2.

The following equation is applied as a fundamental equation to evaluate the attenuation properties;

$$
L_{V A}(f)-L_{V A 0}(f)=-10 \log \left(R / R_{0}\right)-8.68 \alpha(f)\left(R-R_{0}\right)
$$

where $L_{V A}(f)$ is the vibration acceleration level in the vertical direction of the ground surface at $f \mathrm{~Hz}, L_{V A O}(f)$ the vibration acceleration level in the radius direction of arch at $f \mathrm{~Hz}, R$ propagation distance from the reference point (see Fig.7), $R_{0}$ distance from the source to the reference point and $\alpha(f)$ is the material damping coefficient at $f \mathrm{~Hz}$. In this equation, the geometrical damping coefficient is determined to be 0.5 under the following assumptions: shield tunnels are infinitely long structures existing in the ground and vibration propagated from tunnels is body wave from buried line source.

The material damping coefficient $\alpha$ in every one-third octave band is calculated as shown in Fig. 8 by using the Eq. (1). $L_{V A}(f)$ and $\mathrm{L}_{\mathrm{VA} 0}(f)$ are obtained by field measurement. As some measurement points are located on the ground surface, the $\alpha$ value is decided by means of the regression analysis with a logarithmic regression equation. The figure indicates that the value of $\alpha$ tends to increase as frequency becomes higher. In the frequency band of 10 to $40 \mathrm{~Hz}$, in which wave length is short, the $\alpha$ values are negative values at almost all sites. It is considered that the occurrence of negative values is caused by the amplification near the ground surface. The relationship between frequency $f$ and the material damping coefficient $\alpha$ is formulated by regression analysis based on the average values of $\alpha$ of 14 locations under the assumption that $\alpha$ and $f$ are linear relationship. The following equation is obtained as;

$$
\alpha(f)=0.001 f-0.06
$$

As the equations (1) and (2) enable us to calculate the attenuation in the ground, vibration acceleration level on the ground surface in one-third octave band is calculated by using the spectrum calculated by the train/track/tunnel interaction model (see Fig.6.).

Table 2 Conditions of measurement locations

\begin{tabular}{l|l}
\hline Cover depth & $11.5 \mathrm{~m}-28.3 \mathrm{~m}$ \\
\hline Tunnel type & Shield tunnel \\
\hline Outer diameter & $\begin{array}{l}\text { Linear motor small subway: } 5.3 \mathrm{~m}, 8.5 \mathrm{~m} \\
\text { Ordinary subway: } 7.3 \mathrm{~m}, 10.4 \mathrm{~m}\end{array}$ \\
\hline Ground condition & Alluvial ground, Diluvial ground \\
\hline Length of car & $\begin{array}{l}\text { Linear motor subway: } 16 \mathrm{~m} \\
\text { Ordinary subway: } 20 \mathrm{~m}\end{array}$ \\
\hline Train speed & $38 \mathrm{~km} / \mathrm{h}-69 \mathrm{~km} / \mathrm{h}$ \\
\hline Track condition & $\begin{array}{l}\text { Directly fastened track, Ballast track, } \\
\text { Vibration-reduction sleeper track }\end{array}$ \\
\hline
\end{tabular}

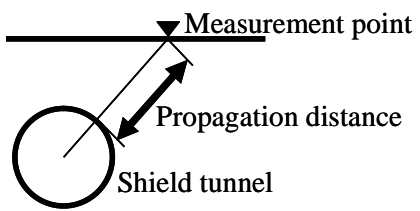

Fig.7 Definition of propagation distance
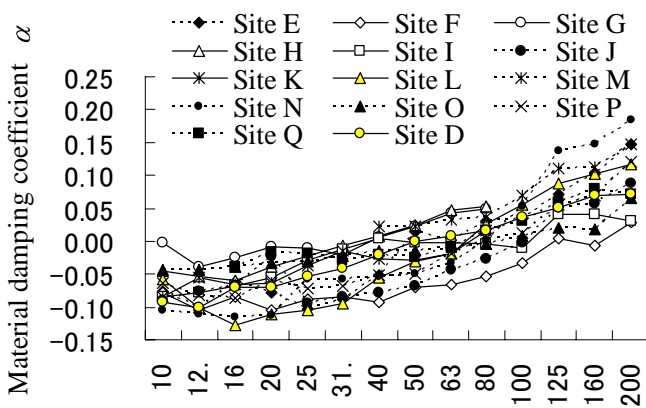

$1 / 3$ octave band center frequency $[\mathrm{Hz}]$

Fig.8 Relationship between frequency and $\alpha$ 


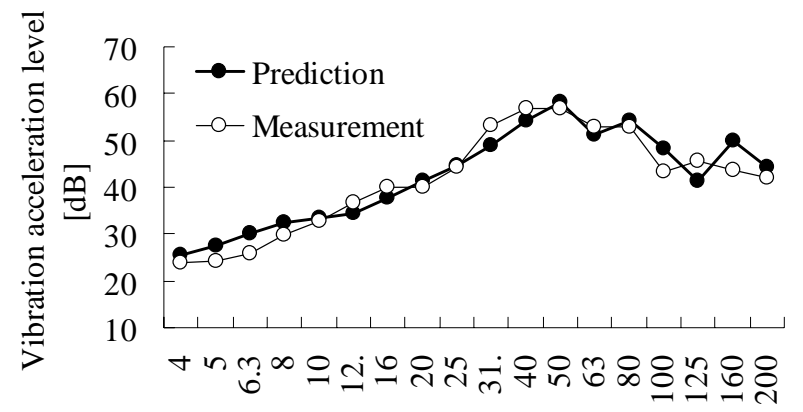

Frequency [Hz]

(a) J3, Z-direction

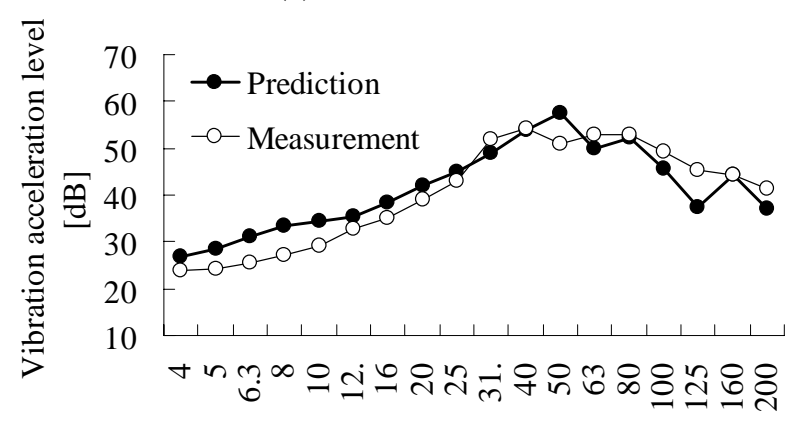

Frequency $[\mathrm{Hz}]$

(b) J7, Z-direction

Fig.9 Comparison between predicted and measured one-third octave band spectra (ref $10^{-5} \mathrm{~m} / \mathrm{s}^{2}$ )

Calculated results are agreement with measurement ones as shown in Fig.9.

\subsection{Numerical calculation (2D-FE analysis)}

Vibration propagation in the ground is calculated by means of 2D-FE analysis under the same condition as the field measurement (see chapter 2). Figure 10 shows the FE analysis mesh, which includes 3,864 isoparametric eight-node elements and 11,906 nodes. The length of element in the vertical direction is mostly $0.6 \mathrm{~m}$, and intervals of two continuous nodes are approximately $0.3 \mathrm{~m}$. To prevent the reflection of vibration at the boundaries, the unified viscous boundary condition is arranged on the perimeter of analytical area. Rayleigh damping is applied to this calculation under the following equation as;

$$
\mathrm{C}=\alpha \mathrm{M}+\beta \mathrm{K}
$$

where $\mathrm{C}$ is damping matrix, $\mathrm{M}$ Mass matrix, $\mathrm{K}$ Stiffness matrix and $\alpha$ and $\beta$ are constants. A consistent mass matrix and Newmark's beta method, which is one of the direct integral analyses, are applied in this numerical calculation.

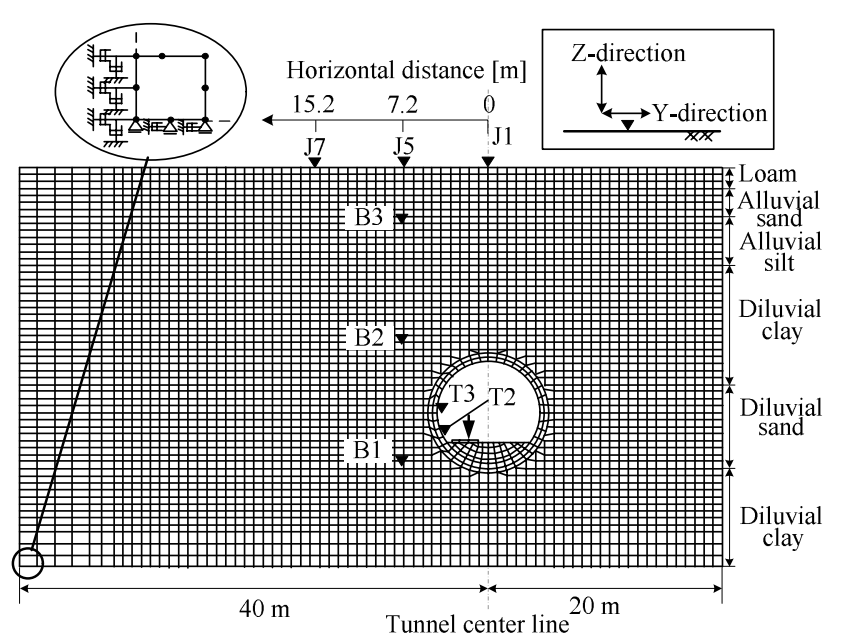

Fig.10 Calculation model (2D-FE analysis)

Table 3 Constants $\alpha$ and $\beta$

\begin{tabular}{l|c|c}
\hline & $\alpha$ & $\beta$ \\
\hline \hline Ground & 6.221 & $6.303 \times 10^{-5}$ \\
\hline Tunnel & 0.377 & $1.582 \times 10^{-6}$ \\
\hline
\end{tabular}

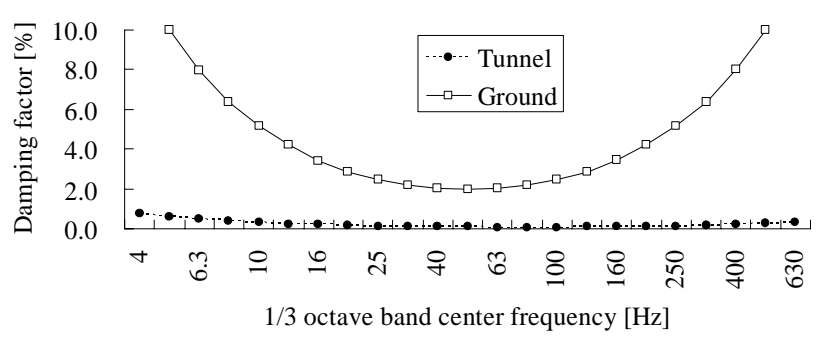

Fig.11 Relationship between frequency and damping factor

The modulus of elasticity of the ground is calculated based on the shear wave velocity obtained by P-S logging, while that of the tunnel was decided to be $5,460 \mathrm{MN} / \mathrm{m}^{2}$ by assuming that shear wave velocity is $1,000 \mathrm{~m} / \mathrm{s}$. The values of constants $\alpha$ and $\beta$ in the ground are determined as shown in Table 3 to satisfy the condition that the damping coefficient $(h)$ are ranging from 2 to $5 \%$ when frequency varied from 10 to $250 \mathrm{~Hz}$ (see Fig.11). The time-history acceleration amplitude during 1.024 second is input at the node corresponding to the position near the track. The calculation uses the time-history acceleration amplitude obtained by train/track/tunnel interaction model (see Fig.5).

The time-history acceleration amplitude of representative points is analyzed by the FFT. The overall values of vibration acceleration level (abbreviated as "VAL (overall)") and VAL in $1 / 3$ octave bands are shown in Table4 and Fig.12, respectively. Slight differences of 0.7 to $3.6 \mathrm{~dB}$ are observed between the calculated and measured VAL (overall) on the ground surface, while the 
Table 4 Comparison between calculated and measured vibration acceleration level $[\mathrm{dB}]\left(\right.$ ref $\left.10^{-5} \mathrm{~m} / \mathrm{s}^{2}\right)$

\begin{tabular}{l|cccccc}
\hline Location & \multicolumn{2}{|c}{$\mathrm{B} 2$} & \multicolumn{2}{c}{$\mathrm{J3}$} & \multicolumn{2}{c}{ 77 } \\
\hline Direction & $\mathrm{Z}$ & $\mathrm{Y}$ & $\mathrm{Z}$ & $\mathrm{Y}$ & $\mathrm{Z}$ & $\mathrm{Y}$ \\
\hline Calculation & 62.4 & 61.6 & 58.7 & 68.6 & 61.1 & 65.9 \\
\hline Measurement & 66.0 & 67.9 & 62.3 & 69.4 & 60.4 & 63.8 \\
\hline Difference & -3.6 & -6.3 & -3.6 & -0.8 & +0.7 & +2.1 \\
\hline
\end{tabular}

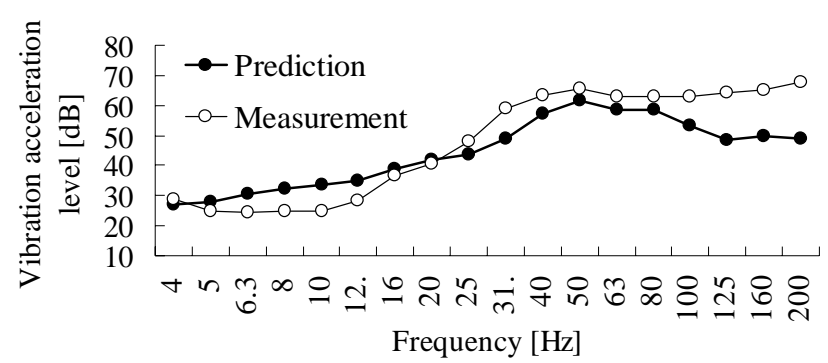

(a) T3, Z-direction (on tunnel lining)

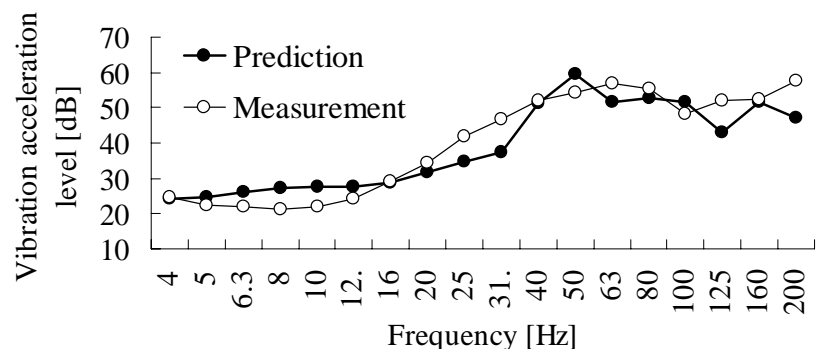

(b) B2, Z-direction (in the ground)

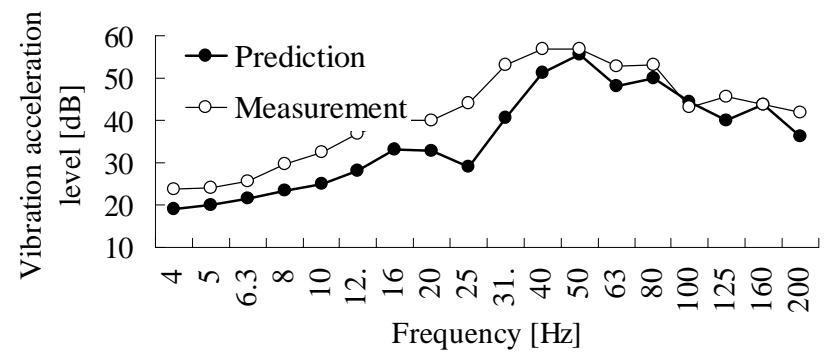

(c) J3, Z-direction (on the ground surface)

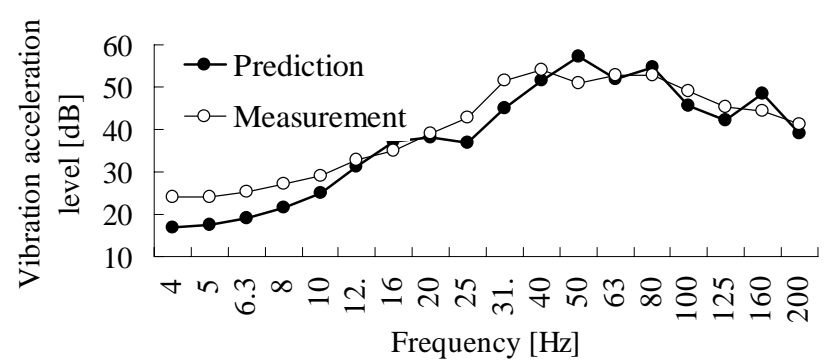

(d) J7, Z-direction (on the ground surface)

Fig.12 Comparison between calculated and measured one-third octave band spectra (ref $10^{-5} \mathrm{~m} / \mathrm{s}^{2}$ )

calculated value is $6.3 \mathrm{~dB}$ smaller than measured one at B2 in the borehole. Figure 12 reveals that the calculated spectra are roughly agreement with measured ones in the tunnel, in the ground and on the ground surface.

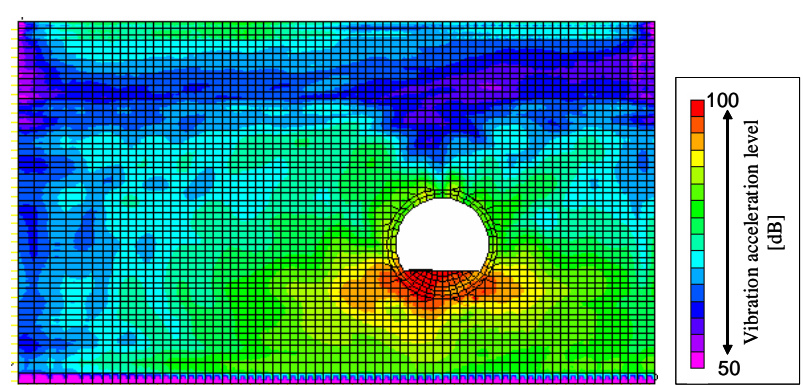

Fig.13 Contour of overall values of vibration acceleration level (vertical direction)

The contour of VAL (overall) in the Z-direction is shown in Fig.13. It is found that vibration radiates from the bottom of tunnel. The vibration attenuates toward the ground surface below the depth of $4 \mathrm{~m}$, while the amplification of vibration is observed near the ground surface. The maximum VAL (overall) on the ground surface does not appear just above the tunnel center, but is located approximately 10 to $20 \mathrm{~m}$ apart from the tunnel center line. It may be considered that the amplification is caused by the soft ground near the ground surface and the free surface condition.

\section{3 three-dimensional numerical calculation}

If the vibration induced by high-speed trains or propagated from deep tunnel, propagation time from tunnels to ground surface becomes longer as compared with time during train pass-by and the assumption of simple 2-D problem cannot be applied. Furthermore, it is necessary to consider the 3-D problem in order to investigate the vibration propagated to buildings, which has finite width.

3-D calculation is, therefore, tried to be carried out by using the model described in Fig.12. The calculation code LS-DYNA is used in this calculation. The calculation model has 63,503 elements and the used material properties are same as the 2-D calculation. The time-history acceleration amplitude near the track during the passage of one-bogie is input at the node corresponding to the location passing the bogie at the analysis I, while that during the passage of eight-car (16 bogies) is input at the analysis II.

The example of calculation results are shown in Fig.13, comparing with the measurement results. The calculated results are not agreement with those obtained by measurement. This calculation, however, shows the possibility to apply detailed 3-D calculation to the investigation of subway-induced vibration. 


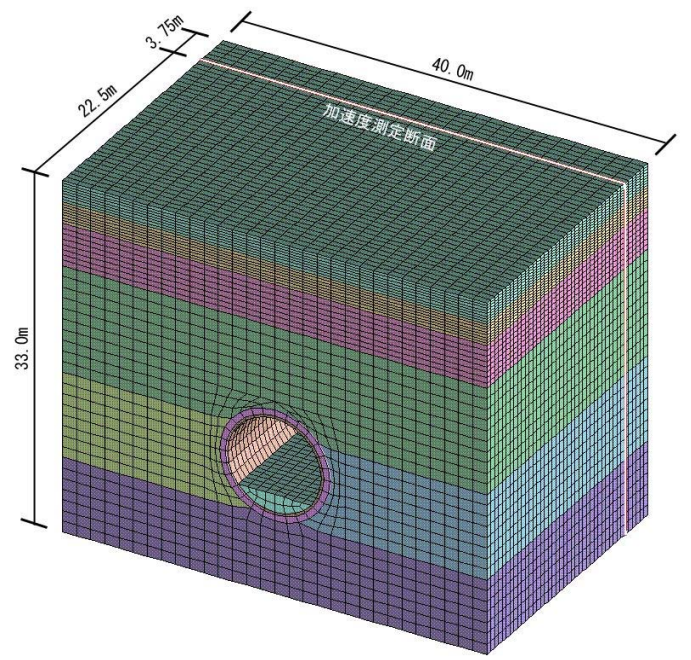

Fig.12 Calculation model (3D) [9]

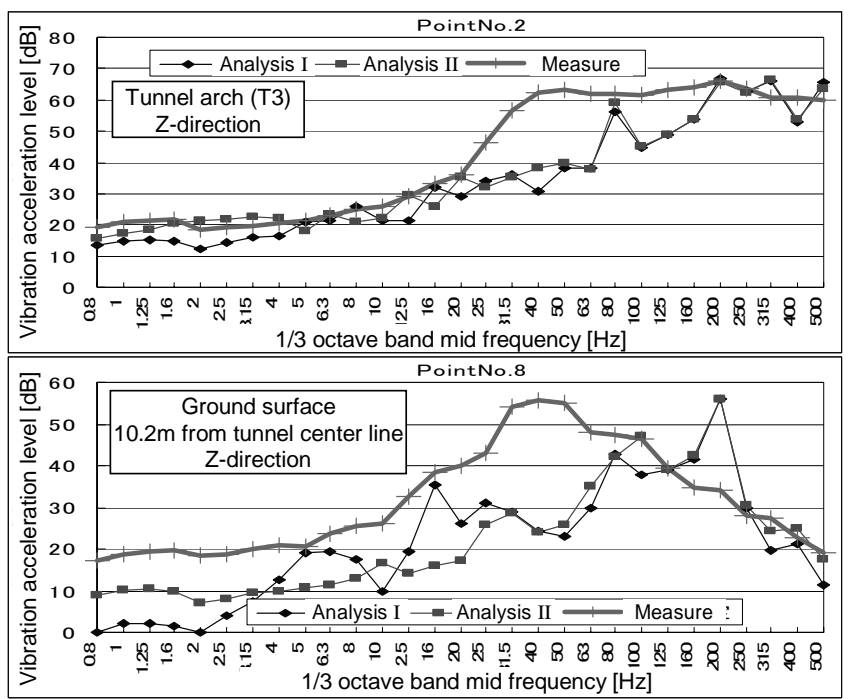

Fig.13 Calculation results [9]

\section{CONCLUSION}

This paper describes the investigation of prediction method for the propagated subway-induced vibration based on the model for train/track/tunnel and that of wave propagation in the ground. The following results are derived.

1) Field measurement in a subway shield tunnel, in the ground and on the ground surface reveals that high-frequency components gradually attenuate in the ground and absolute peaks are observed at $50 \mathrm{~Hz}$ on the ground surface

2) The calculation example shows that the train/track/ tunnel interaction model is usable to predict the time-history acceleration amplitude and the VAL in $1 / 3$ octave bands of vibration generated in tunnels.
3) Empirical model is proposed to predict the attenuation in the ground in $1 / 3$ octave bands and enables us to conveniently predict the VAL in $1 / 3$ octave bands on the ground surface.

4) The calculation example reveals that $2 \mathrm{D}-\mathrm{FE}$ analysis is usable to predict the time-history acceleration amplitude and the VAL in 1/3 octave bands in tunnels, in the ground and on the ground surface. It is possible to obtain the distribution of VAL in the ground by the 2D-FE analysis.

5) The trial calculation shows the possibility to apply detailed 3-D calculation to the investigation of subway-induced vibration.

\section{REFERENCES}

[1] Shito, K.: Application cases of estimation method of environmental vibration - subway-induced vibration, Technical report of Institute of Nose Control Engineering Japan, No20, 20-26 (1997). (in Japanese)

[2] Furuta, M. and Abe, K.: Time domain analysis method for track/wheel interaction, Journal of the Japan Society of Civil Engineers, Vol.583, IV-38, 61-70 (1998). (in Japanese)

[3] Abe, K., Satou, D., Suzuki, T. and Furuta, M.: three-dimensional analysis of subway track vibrations due to running wheels, Proc. the international workshop Wave2002, 149-156 (2002).

[4] Tsuno, K., Furuta, M. Fujii, K., Nagashima, F. and Kusakabe, O.: Wide range attenuation properties of ground vibration propagated from subway shield tunnel, Journal of the Japan Society of Civil Engineers, No.792, III-71, 185-197 (2005). (in Japanese)

[5] Furuta, M. and Nagashima, F.: Dynamic response analysis of subway -induced vibration on shield tunnel - Ground system, and calculation example, Proc. of Tunnel Engineering, JSCE, Vol.4, 93-100 (1994). (in Japanese)

[6] Fujii, K., Takei, Y. and Tsuno, K.: Propagation properties of train-induced vibration from tunnels, Quarterly Report of RTRI, Vol.46, No.3, 194-199 (2005).

[7] Abe, K., Suzuki, T. and Furuta, M.: Identification of rail-surface irregularity for railway track vibration analysis, Journal of applied mechanics, Vol.3, 107-114 (2000). (in Japanese)

[8] Tsuno, K.: Propagation properties of train-induced vibration from tunnels, Proceedings of the workshop "noise and vibration" in Porto, 191-215 (2008).

[9] Matsumoto, D., Furuta, M. and Nagashima, F.: An analytical study on subway induced ground vibration by 3D Finite Element Method, Proc. of J-rail 2006, 